\title{
Mark Easterby-Smith
}

Lancaster University, UK

Shenxue Li

University of Strathclyde Business School, UK

\section{Jean Bartunek}

Carroll School of Management Boston College, USA

\section{Research Methods for Organizational Learning: The Transatlantic Gap}

\begin{abstract}
Research design has a notable impact on the nature of management and organizational research, and there have been numerous mentions, largely anecdotal, of differences in research design between journals published in the UK and USA. This article describes a systematic study of these supposed differences through content-analysis of 295 articles about organizational learning published in eight leading British-and US-based journals over the past 20 years. The results demonstrate substantial differences in data sources, data collection, and the scale of investigations. We discuss their impact on gaps in the study of organizational learning and offer our own thoughts on possible solutions (as well as challenges) for bridging these gaps. Key Words: organizational learning; research methods; UK; USA
\end{abstract}

England and America are two countries separated by the same language.

(George Bernard Shaw, 1942)

\section{Introduction}

Organizational learning (OL) has garnered significant research interest in the past two decades, and is increasingly considered a key area in management and organizational research (Bapuji and Crossan, 2004; Easterby-Smith and Lyles, 2003; Edmondson, 2002; Vince et al., 2002). Our count of research articles about OL published in eight leading British and US journals between 1988 and 2007 
(see Table 1) indicates that there have been 455 publications on this topic, and the number of articles on it continues to grow rapidly (see Figure 1). Of this large number of publications, about 27 per cent appeared in Management Learning $(M L)$.

The proliferation of research in OL suggests that there is much to appreciate and to be proud of in our field's and ML's history. At the same time, as the volume of organizational learning research continues to grow, it is useful to take stock of what we have. Given $M L$ 's status as one of the largest contributors to publications about organizational learning, its 40th anniversary is an appropriate occasion to explore one particularly important dimension of research in this field, the supposed methodological divide between the types of publications on this topic that appear in journals based in the UK and the USA.

There have been numerous mentions, largely anecdotal, of separate research traditions which may significantly affect the types of research likely to be published in journals located on particular continents (Beyer, 1997; EasterbySmith et al., 2000; Eden and Rynes, 2003; Schminke and Mitchell, 2003). Easterby-Smith et al. (2000), for example, note that European research relies much on interpretative methods, and North American studies are more likely to follow a strong quantitative tradition. Koza and Thoenig (1995) identified other potential differences in the data collection techniques and scales of investigation between European and North American organizational studies. They reinforce the perception that European journals are more likely to publish qualitative single-case studies, while North American journals are more likely to publish quantitative analyses of sample surveys.

Though providing useful insights, these claims have not yet been supported by empirical evidence. In this short article we explore the perceived differences by mapping and contrasting research methods and research designs published in UK- and US-based journals about the field of OL. We will demonstrate, following the quotation from Shaw in the epigraph, that despite outward similarity, there

Figure 1 Articles on organizational learning published in four UK and four US journals between 1988 and 2007

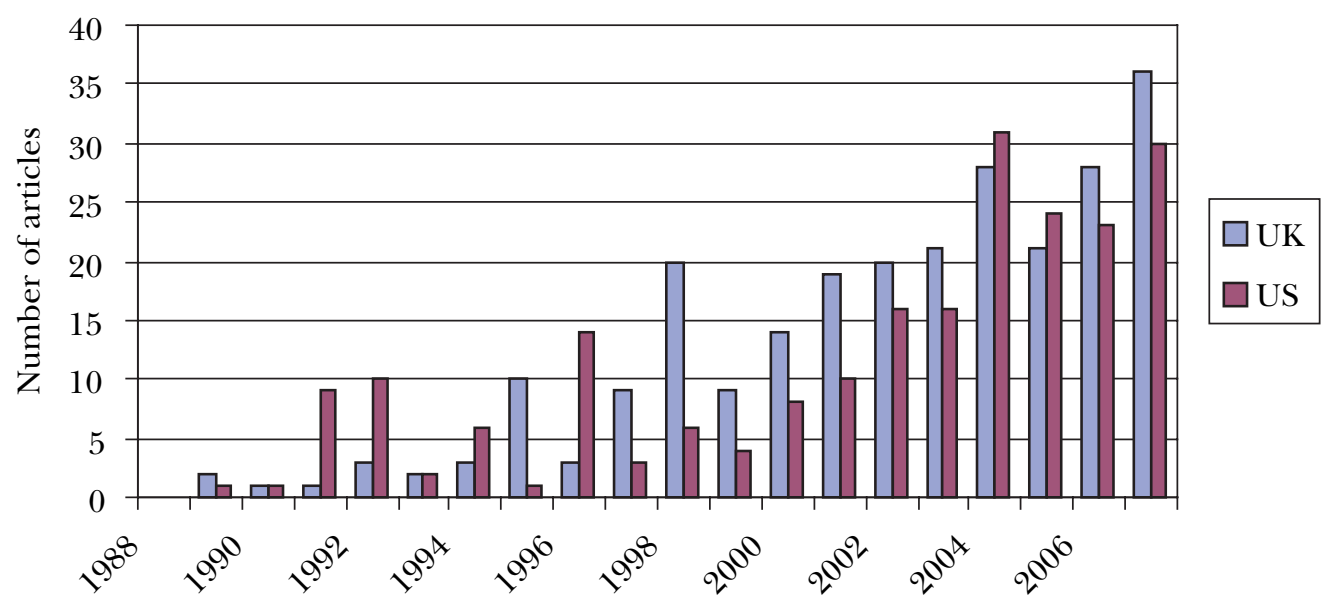

Publication year 
are indeed some major differences between the two sets of journals. We then discuss potential impacts of these differences in limiting the evolution of study of OL. Finally we offer some thoughts on possible solutions (as well as challenges) for bridging the gaps between them.

\section{Research Methods}

We content-analysed the empirical articles in organizational learning that appeared in four British-based and four US-based journals between 1988 and 2007 (see Table 1). These journals were selected based on four considerations. First, we wanted to include only highly rated management and organization journals as shown in the Social Science Citation list, Harzing's journal quality list, ABS journal list, and several previous studies of influential journals (e.g. Johnson and Podsakoff, 1994; Park and Gordon, 1996; Tahai and Meyer, 1999). Second, we wanted to include journals that published comparatively large numbers of articles on organizational learning (Easterby-Smith and Lyles, 2003). Third, although recognizing that all journals are seeking to internationalize their appeal, we wanted to include only journals that retain primary editorial roots and control in either the UK or the USA. Thus, journals with cross-national control and ownership, such as Organization Studies (Usdiken and Pasadeos, 1995; Koza and Thoenig, 1995) were excluded. Finally, we decided to exclude journals that did not accept empirical pieces. Hence, those which only published conceptual reviews, such as the Academy of Management Review, were not included. The eight journals we selected represent the leading UK- and US-based empirical outlets for high quality management and organizational research that regularly publish articles on organizational learning.

Our main criterion for including an article was that it should empirically address an issue related to organizational learning. Thus, we omitted editorials, commentaries, theoretical pieces, and book reviews. In all, we content analysed 295 empirical articles.

Table 1 Count of articles reviewed by journal

\begin{tabular}{lllc}
\hline Journal & Abbreviation & Country & Number of articles \\
\hline Academy of Management Journal & AMJ & USA & 39 \\
Administrative Science Quarterly & ASQ & USA & 18 \\
British Journal of Management & BJM & UK & 18 \\
Human Relations & HR & UK & 16 \\
Journal of Management Studies & JMS & UK & 36 \\
Management Learning & ML & UK & 61 \\
Organization Science & OS & USA & 37 \\
Strategic Management Journal & SMJ & USA & 70 \\
Total & & & $295^{*}$ \\
\hline
\end{tabular}

* These were all of the empirical articles including 131 UK and 164 US studies within a total sample of 455 articles published on organizational learning between 1988 and 2007. 
The focus of our content analysis was the research design of the studies. This included whether data came from primary or secondary sources, the type of data (qualitative, quantitative, both, or experiments/simulations), whether the study explored one case or multiple cases, and whether the study took place in one or multiple industries.

\section{The Findings}

Table 2 presents counts of the OL articles in the British and US journals. Given the differing sample sizes for UK- and US-based journals, we compared the proportions of the use of particular types of methodologies, and found considerable differences.

The use of primary $v$. secondary data. One substantial difference in research design between studies published in the UK- and US-based journals was found in their data sources. Of the empirical studies of OL published in the British journals, 93 per cent relied on primary data. By contrast, only 59 per cent of the empirical articles investigating OL published in the US-based journals used primary data.

Qualitative v. quantitative data. A second substantial difference in research design between OL studies published in UK and US journals was in the data collection techniques employed. In the British journals, 68 per cent of the empirical studies of OL employed qualitative techniques such as in-depth interviews and observation as the primary research strategy, compared with 15 per cent for articles in the US journals.

Scale of investigation. A third substantial difference in research design between the two sets of journals was found in the scale of investigation. About 76 per cent of the OL articles published in the British journals use case studies. By contrast, only 38 per cent of the OL articles published in the US articles use case studies. In addition, only 24 per cent of the studies published in British journals are generalized across single/multiple industries, compared with 62 per cent for articles published in the US journals.

Taken together, our results indicate that, with respect to OL, some perceptions based on anecdotal evidence are essentially correct. In their publications about organizational learning, in comparison with US journals, British-based journals are much more likely to publish articles relying on primary data, to use qualitative methodologies and case studies, and to focus on single, opposed to multiple, industries.

\section{Implications for the Evolution of Organizational Learning Research}

Do these differences matter, and what are their implications for the evolution of scholarship and research in OL?

Organizational learning is a dynamic and complex field (Easterby-Smith and Lyles, 2003; Vince et al., 2002). Given the complexity of the issues faced in the field, a diversity of research designs is likely to reflect its multiple components more fully. When the publications in the UK and US journals are viewed together, considerable diversity in the research methods used is evident; but when 


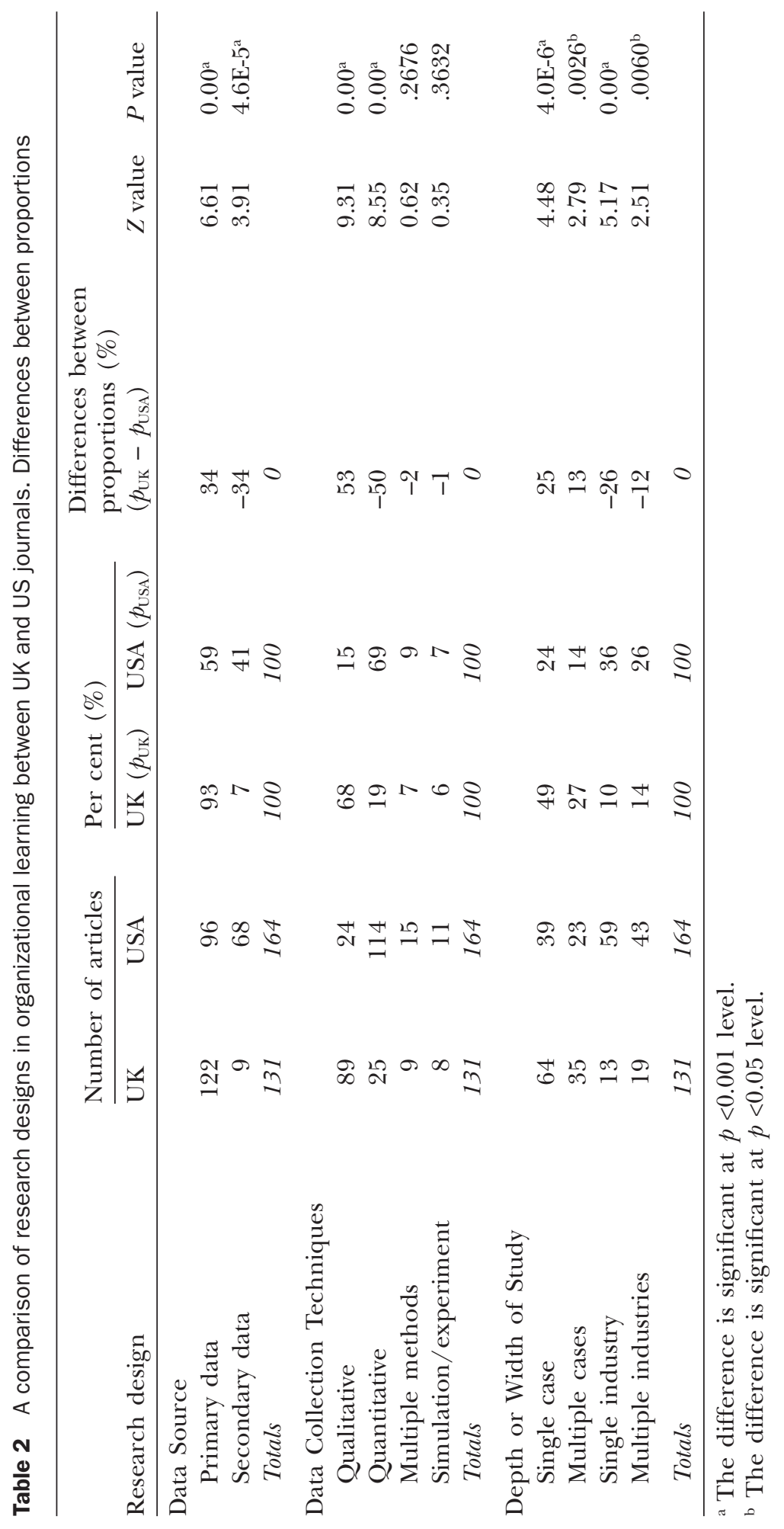


they are viewed separately, the comparatively limited set of research methods employed in articles published on each side of the Atlantic is much less diverse. A potential critique of the British tradition as indicated by articles published in UK journals, is that it places too much emphasis on theory building based on micro-level managerial phenomena; and it overuses case studies, which make the generalizability of the research results very difficult. Although being interesting and adding new meanings to quantitative research (Bartunek and Seo, 2002), contextualized exploratory case analysis does not make it possible to test the relationship between managerial phenomena and the learning results (EasterbySmith et al., 2000; Vince et al., 2002).

Articles published in US journals, on the other hand, can be critiqued for placing too much emphasis on quantitative techniques. These are suitable for testing objective phenomena and macro-level management and organizational issues, but less likely to uncover important complex process issues such as cognitive and interactive phenomena in organizational learning.

Although the two research traditions seem complementary, clearly, the in-depth micro-level learning issues emphasized more frequently by articles published in British journals have not been tested as often by generalizable instruments, and the macro-level issues published more frequently in US journals do not, as often as they might, explain in depth why and how learning takes place within organizations. The methodological divide between the two sets of journals therefore constrains the development and accumulation of knowledge of OL, contributing to the fact that it remains largely a 'black box' (Easterby-Smith et al., 2004: 378) even after two decades' rapid growth in the number of studies on the topic.

\section{Bridging the Gap: Possible Solutions and Challenges}

Perhaps it is time to open the box. Perhaps it is time to consider what to do about the research traditions reflected in the two sets of journals. In order that the diversity they reflect may be fruitful for stimulating a more comprehensive and integrated understanding of OL, we make three suggestions.

First, we suggest that business schools change their traditional research training curricula to ensure more balance between qualitative and quantitative methods. Historically, doctoral training in US business schools has adopted primarily a positivist approach to management and organizational research, originally influenced by the Ford Foundation report (Gordon and Howell, 1959) which recommended the adoption of scientific methods to test for generalizable theories without consideration for the specific nature of the inquiry (Üsdiken and Pasadeos, 1995). This is changing, but there is still considerable room for development of qualitative methods. For example, most doctoral training programmes in North American universities provide no more than one or two qualitative sessions within a course (Easterby-Smith et al., 2008a). To strengthen the qualitative elements in research training would be an immediate step towards pursuing qualitative research in the US.

Scholars in the UK, on the other hand, have historically borrowed research methods from other social science disciplines, which have been particularly 
strong in qualitative methods. Many British academics were therefore trained in management schools that focused on interpretative theories based on the study of micro-level management and organizational phenomena. Given that little quantitative training has been incorporated in British research programmes, it is important for doctoral training to cover qualitative and quantitative methods in equal measure as currently required by the Economic and Social Research Council (ESRC) which funds doctoral training in the UK (Easterby-Smith et al., 2008b). Of course, changing training traditions represents a real challenge. Apart from potential individual resistance to such changes there are institutional difficulties to overcome, and it will take time to rectify the shortage of qualified teaching and reviewing expertise in the research methodologies more emphasized in the other country.

Second, we suggest that researchers in the UK and USA strengthen their engagement in cross-border research collaboration in ways that contribute to the benefits of the research traditions of both countries. Consider the relative size of the two countries. The USA is much larger, and the abundance of plants and businesses means that large-scale surveys are necessary to understand overall patterns. The UK is a smaller economy, which means that smaller surveys and case studies may be able to provide data that is sufficiently comprehensive. Cross-border collaborations offer the possibility to combine these strengths in the service of producing more desirable multi-method research. The ESRC, for example, could extend its calls beyond the UK research community to include US scholars and encourage UK-US collaboration in which transatlantic researchers could combine qualitative and quantitative methods to provide a more complete picture of a phenomenon than either methodology could accomplish alone. This of course also represents a real challenge. Issues of cross-border communication, research costs and so on are often significant barriers to surmount.

Finally, we hope that current efforts to internationalize leading management journals will be sustained through diversifying networks of editors, reviewers and authors, and through editorial receptivity to research that expands journals' historical traditions with respect to research approaches To this end, journals could make an explicit point of encouraging international contributions that fall outside their traditions (Easterby-Smith et al., 2008a; Eden and Rynes, 2003). For example, they could emphasize the journal's receptive policy to non-traditional papers in the form of supportive editorials (Rynes, 2004). This is particularly relevant to US journals given their dominant position in publishing OL. Other management and organizational research journals could also signal their changes of policies through commissioning Special Issues that emphasize balanced use of qualitative and quantitative methods. In addition, specialized journals could follow the lead of $M L$, which currently collaborates with the transatlantic academic association, Organizational Learning, Knowledge and Capabilities (OLKC), to organize open forums discussing research challenges in OL and their corresponding policies.

In addition, given that there is not sufficient appreciation of each other's research tradition we suggest the use of 'boundary spanners', an idea that one of us proposed for the purpose of enhancing academic-practitioner relationships (Bartunek, 2007). In our context, boundary spanners refer to people who have dual expertise in qualitative and quantitative research and who treat both traditions as of value and as having something to contribute to the other. 
Since boundary spanners go beyond the usual limits of both qualitative and quantitative perspectives, they may forge new paths for mutual understanding and collaboration. An important consideration journals could make is to have at least some boundary spanners serving on their editorial review boards. The challenge, of course, is how to develop a sufficient number of boundary spanners. In addition to balanced training and transatlantic research collaboration as what we discussed earlier, more efforts could be made through education exchange initiatives and international visiting scholarships (Drejer et al., 2000).

\section{Conclusion}

Our findings validate anecdotally based claims that there are substantial differences in research design between UK and US journals' publications about organizational learning. Results of our study strongly support previous discussions regarding the methodological divide between European and American management and organizational research (Easterby-Smith et al., 2000; Hinings, 1988; Koza and Thoenig, 1995; Üsdiken and Pasadeos, 1995).

Although they may not be surprising findings, the differences between UK and US research methods predominantly published in UK and US journals constrain the accumulation of knowledge of OL; neither is sufficiently broad to foster the rather complex growth and maturation of the learning paradigm. The methodological divide between the two research traditions serves as a limitation to their contributions to the evolution of management and organizational research on OL. Dialogue between the continents is clearly required, and this will take the efforts of all concerned. The foregoing three suggestions are intended as discussion points with which to begin the dialogue.

\section{Acknowledgement}

We are grateful to the Economic and Social Research Council's Advanced Institute of Management (AIM) Initiative for providing support for this paper under Award No: 331-25-0018.

\section{References}

Bapuji, H. and Crossan, M. M. (2004) 'From Questions to Answers: Reviewing Organizational Learning Research', Management Learning 35(4): 397-417.

Bartunek, J. M. (2007) 'Academic-Practitioner Collaboration Need Not Require Joint or Relevant Research: Toward a Relational Scholarship of Integration', Academy of Management Journal 50(6): 1323-33.

Bartunek, J. M. and Seo, M. -G. (2002) 'Qualitative Research Can Add New Meanings to Quantitative Research', Journal of Organizational Behavior 23(2): 237-42.

Beyer, J. M. (1997) 'Building on Past Strengths with Incremental Change', Academy of Management Journal 40(6): 1436-41.

Drejer, A., Blackmon, K. and Voss, C. (2000) 'Worlds Apart?-A look at the Operations Management Area in the US, UK and Scandinavia', Scandinavian Journal of Management 16: $45-66$. 
Easterby-Smith, M. and Lyles, M. (2003) 'Re-reading Organizational Learning: Selective Memory, Forgetting, and Adaptation', Academy of Management Executive 17(2): 51-5.

Easterby-Smith, M., Crossan, M. and Nicolini, D. (2000) 'Organizational Learning: Debates Past, Present and Future', Journal of Management Studies 37(6): 783-96.

Easterby-Smith, M., Golden-Biddle, K. and Locke, K. (2008a) 'Working with Pluralism: Determining Quality in Qualitative Research', Organizational Research Methods 11(3): 418-29.

Easterby-Smith, M., Thorpe, R. and Jackson, P. (2008b) Management Research. London: SAGE.

Easterby-Smith, M., Antonacopoulou, E., Simm, D. and Lyles, M. (2004) 'Constructing Contributions to Organizational Learning: Argyris and the Next Generation', Management Learning 35(4): 371-80.

Eden, D. and Rynes, S. (2003) 'From the Editors', Academy of Management Journal 46(6): 679-83.

Edmondson, A. C. (2002) 'The Local and Variegated Nature of Learning in Organizations: A Group-Level Perspective', Organization Science 13(2): 128-46.

Gordon, R. A. and Howell, J. E. (1959) Higher Education for Business. Ford Foundation.

Hinings, B. (1988) 'Defending Organization Theory: A British View from North America', Organization Studies 9(1): 2-7.

Johnson, J. L. and Podsakoff, P. M. (1994) 'Journal Influence in the Field of Management: An Analysis Using Salancik's Index in a Dependency Framework', Academy of Management Journal 37(5): 1392-407.

Koza, M. P. and Thoenig, J. -C. (1995) 'Organizational Theory at the Crossroads: Some Reflections on European and United States' Approaches to Organizational Research', Organization Science 6(1): 1-8.

Park, S. H. and Gordon, M. E. (1996) 'Publication Records and Tenure Decisions in the Field of Strategic Management', Strategic Management Journal 17(2): 109-28.

Rynes, S. (2004) 'From the Editors', Academy of Management Journal 47(4): 454.

Schminke, M. and Mitchell, M. (2003) 'From the Editors', Academy of Management Journal 46(3): 279-82.

Shaw, G. B. (1942) 'Picturesque Speech and Patter', Reader's Digest November: 100.

Tahai, A. and Meyer, M. J. (1999) 'A Revealed Preference Study of Management Journals’ Direct Influences', Strategic Management Journal 20(3): 276-96.

Üsdiken, B. and Pasadeos, Y. (1995) 'Organizational Analysis in North America and Europe: A Comparison of Co-Citation Networks', Organization Studies 16(3): 503-27.

Vince, R., Sutcliffe, K. and Olivera, F. (2002) 'Organizational Learning: New Directions', British Journal of Management 13(S2): S1-6.

\section{Contact Addresses}

Mark Easterby-Smith is Professor of Management Learning and Associate Dean, Enterprise at Lancaster University Management School, Lancaster LA1 4YX, UK.

[email: m.easterby-smith@lancaster.ac.uk]

Shenxue Li is Lecturer of Strategy/International Management in the Department of Management, University of Strathclyde Business School, 199 Cathedral Street, Glasgow G4 OQU, UK.

[email: shenxue.li@strath.ac.uk]

Jean Bartunek is Robert A. and Evelyn J. Ferris Chair, Professor of Organization Studies at Carroll School of Management, Boston College, Fulton Hall 430C, 140 Commonwealth Ave. Chestnut Hill, MA 02367-380, USA.

[email: bartunek@bc.edu] 